\title{
GAMIFICANDO O ENSINO DA LITERATURA: UMA EXPERIÊNCIA DE JOGABILIDADE NO ENSINO MÉDIO INTEGRADO COM O JOGO CREALIT
}

\author{
Daniel Everson da Silva Andrade - IFPB - daniel.andrade@ifpb.edu.br \\ https://orcid.org/0000-0002-8129-8624 \\ Josilene Almeida Brito-IF SertãoPE-josilene.brito@ifsertao.edu.br \\ https://orcid.org/0000-0002-4536-5981 \\ Francisco Kelsen de Oliveira - IF SertãoPE - francisco.oliveira@ifsertao-pe.edu.br \\ https://orcid.org/0000-0002-7382-3206
}

\begin{abstract}
Resumo: Esta pesquisa teve como objetivo principal investigar a contribuição do ambiente gamificado como ferramenta de incentivo à leitura, de livros clássicos da literatura brasileira, com discentes do Ensino Médio Integrado do Instituto Federal de Educação, Ciência e Tecnologia da Paraíba (IFPB), Campus Cajazeiras, como também no auxílio pedagógico dos docentes no ensino de literatura brasileira. Durante o percurso metodológico adotamos uma pesquisa de caráter aplicado, com procedimentos de pesquisa-ação e abordagem mista qualitativa e quantitativa, tendo como ferramenta de coleta de dados questionários adaptados com questões abertas e fechadas em formato de testes para o público envolvido. Como recurso principal foi desenvolvido um ambiente gamificado (aplicativo) denominado Literatura Criativa (Crealit), e em seguida aplicado junto à turma de alunos. Os resultados verificados foram satisfatórios, pois indicaram que o ambiente gamificado Crealit promoveu habilidades motivacionais como ferramenta de incentivo à leitura na maioria dos alunos participantes da pesquisa.

Palavras-chave: Incentivo à leitura. Gamificação. Ensino Médio Integrado. IFPB.
\end{abstract}

\section{GAMIFYING THE LITERATURE TEACHING: A GAMEPLAY EXPERIENCE IN THE INTEGRATED TEACHING USING THE CREALIT GAME}

\begin{abstract}
This research had as main objective to investigate the contribution of the gamified environment as a tool to encourage reading, of classic books of Brazilian literature, with students the of integrated teaching the Instituto Federal de Educação, Ciência e Tecnologia da Paraíba (IFPB), and in the pedagogical assistance of teachers in the teaching of Brazilian literature. An action research with a mixed qualitative and quantitative approach was used as the methodology. As the main resource was developed a gamified environment (application) called Creative Literature (Crealit). The verified results were satisfactory, as they indicated that the Crealit environment promoted motivational skills as a tool to encourage reading in the majority of students participating in the research.
\end{abstract}

Key words: Encouraging reading. Gamification. Integrated high school. IFPB.

\section{Introdução}

Memórias Póstumas de Brás Cubas, A Moreninha, Vidas Secas e tantas outras obras da bibliografia clássica nacional, são textos de viés canônico que possivelmente iremos ler durante a nossa jornada de estudantes secundaristas. De acordo com a Base Nacional Comum Curricular - BNCC (BRASIL, 2018, p. 523), “[...] tais obras proporcionam o contato com uma linguagem que amplia o repertório linguístico dos jovens e oportuniza novas potencialidades e experimentações de uso da língua, no contato com as ambiguidades da linguagem e seus múltiplos arranjos". A BNCC 
(BRASIL,2018), deixa claro a importância do ensino da leitura englobar o mundo dos games e dos aplicativos (Apps), como facilitadores do processo de ensino aprendizagem.

A formação dos jovens no ensino médio, torna-se uma etapa de investimento e dedicação de tempo nos estudos, de forma imprescindível para enfrentar os desafios e imprevistos que podem desencadear desmotivação, ao se depararem com disciplinas e leituras complexas, provocando falta de interesse e levando-os naturalmente a deixar os estudos sempre para depois. discentes desmotivados e não engajados não se empenharão em realizar suas tarefas de sala de aula, consequentemente a probabilidade de baixo desempenho é bem maior (FALCÃO, 2015).

Dessa forma, as novas tecnologias tornaram-se parte integrante da rotina diária de comunicação intensiva entre os jovens estudantes, como também de entretenimento por meio dos jogos eletrônicos. Corroborando com a necessidade de inovar as experiências de aprendizagem dos jovens estudantes da atualidade, e levando em consideração as habilidades motivacionais despertadas pelos jogos eletrônicos, como favorecedores ao estímulo à leitura. Diversas iniciativas vêm sendo estudadas para melhorar a motivação e o engajamento do estudante, "Dentre elas, uma nova abordagem é a Gamificação (do inglês Gamification)" (Klock et al., 2014, p. 1-2).

No ano de 2002, de acordo com KIM (2015, tradução nossa), o pesquisador Nick Pellin trouxe à tona o termo gamificação, ressignificando o modo como conhecemos os jogos, desde os mais populares jogados em tabuleiros, até os mais sofisticados jogados em consoles. A gamificação veio para trazer soluções de problemas do mundo real através da utilização de elementos de jogos: Dinâmica, Mecânicas e Componentes.

Vale destacar ainda que, a ideia de ludicidade envolta aos softwares permitiu que as interfaces, além de úteis, pudessem ser divertidas - de forma a motivar os usuários por meio de recursos sonoros, imagéticos, assim como propor desafios. Integrando o contexto de ludicidade dos jogos, Liu (2014), contextualiza que os estudantes de hoje nasceram e cresceram envolvidos no mundo virtual dos jogos interativos, das redes sociais e dos videogames de última geração. Segundo Prensky (2001), os discentes de hoje não são mais os mesmos para os quais o nosso sistema educacional foi criado. Chamados de "Digital Natives" (Nativos Digitais, em português) esses discentes, segundo o autor, gastam em média 5.000 horas de suas vidas lendo livros, e 10.000 horas jogando videogames.

Identificamos um baixo índice de empréstimo de livros de literatura brasileira, registrados em alguns relatórios do Sistema de Bibliotecas Integradas do IFPB (Koha-IFPB). Para auxiliar na resolução da inquietude, levantamos dados referentes aos empréstimos realizados em 9 bibliotecas do campi IFPB, no período de 01 de janeiro de 2019 até 01 de janeiro de 2020. Constatou-se que, do total de 28.689 livros emprestados, pela rede de bibliotecas do IFPB em 2019, apenas 3,6\% eram livros de literatura brasileira. No que se refere ao Campus Cajazeiras, unidade onde o pesquisador atua, de um total de 7.474 livros emprestados, em 2019, contou apenas com $4,2 \%$ de empréstimos de livros de literatura brasileira.

Nesse sentido, os dados descritos acima nos motivaram a problematizar a seguinte questão de pesquisa: $\mathrm{O}$ uso de mecanismos de jogos podem favorecer o incentivo à leitura de livros clássicos da literatura brasileira?

Por fim, objetivando responder a questão norteadora da pesquisa, e levando em consideração o perfil dos discentes chamados nativos digitais, foi desenvolvido um ambiente gamificado, modelado com mecânicas de jogos em atividades que favoreçam o estímulo à leitura de livros clássicos. 
O objetivo geral desta pesquisa foi verificar a contribuição do ambiente gamificado (aplicativo) como ferramenta de incentivo à leitura, de livros clássicos da literatura brasileira, nos discentes do Ensino Médio Integrado do IFPB, como também, no auxílio pedagógico dos docentes no ensino de literatura brasileira.

$\mathrm{Na}$ próxima seção faremos uma abordagem dos materiais e métodos utilizados em nossa pesquisa.

\section{Material e Métodos}

Esta pesquisa é de caráter aplicada, com procedimentos de pesquisa-ação com uma abordagem mista qualitativa e quantitativa. Os instrumentos para coleta de dados foram questionários eletrônicos, contendo perguntas abertas e fechadas, cujos dados levantados subsidiaram às avaliações qualitativas (análise do conteúdo), com o intuito de medir o grau de envolvimento e motivação dos discentes, e quantitativos (estatística descritiva) através da escala de Likert, que trata-se de uma mediação através de uma escala de resposta psicométrica, consagrada por sua utilização em questionários que visou medir a opinião dos voluntários da pesquisa (CUNHA, 2007; FIALHO; DIAS; REGO, 2015).

Tendo em vista a proposta de avaliar a contribuição do ambiente gamificado como recurso motivacional ao incentivo à leitura de livros clássicos por discentes do ensino médio integrado do IFPB, nas aulas de literatura, foi identificado a importância de reconhecer na teoria investigada, uma metodologia de avaliação que melhor se adequasse com a proposta apresentada, dessa maneira o questionário foi adaptado com base no modelo ARCS - Attention, Relevance, Confidence, Satisfaction, proposto por (SAVI et al., 2010):

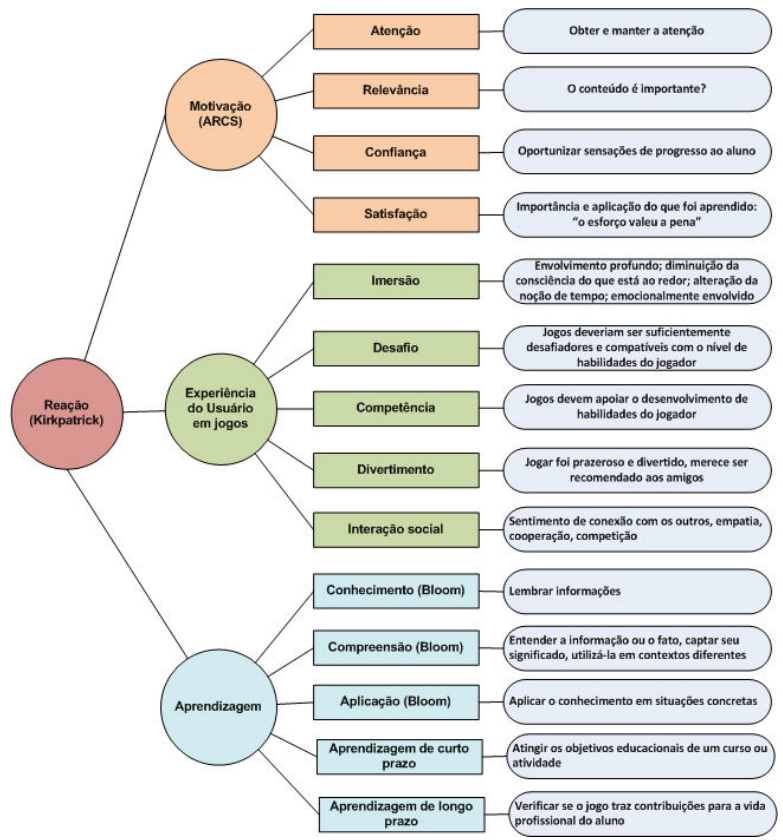

Figura 1 - Modelo de avaliação de jogos educacionais. Fonte: Savi et al. (2010)

O modelo ARCS (SAVI et al. ,2010)) é baseado nas experiências dos usuários, composta de 4 elementos investigativos que são:

1) Foco na reação dos usuários (treinamento de Kirkpatrick);

2) Foco no nível de motivação (O modelo ARCS - Attention, Relevance, Confidence, Satisfaction), buscando avaliar o nível de motivação dos discentes; 
3) A área de experiência do usuário (User eXperience - UX) para avaliar se o ambiente gamificado é agradável/divertido;

4) Taxonomia Bloom visando medir o impacto da aprendizagem dos discentes.

Os sujeitos da pesquisa foram os discentes dos Cursos Técnicos em Informática e Edificações Integrados ao Ensino Médio do IFPB, Campus Cajazeiras, cursando as séries do $1^{\text {a }}$ ao $3^{\mathrm{a}}$. Compreendendo 25 discentes do sexo feminino e 13 do sexo masculino; 5 com idade entre 13 e 15 anos, e 33 com idade entre 16 e 18 anos. Todos dentro da faixa etária da geração Z, nascidos entre 1990 e 2010 . No que se refere a habilidade de leitura de livros, todos leram uma média de 4,96 livros no primeiro semestre de 2020. Quanto ao uso de recursos tecnológicos, todos possuíam smartphones e a grande maioria deixou claro que gostava de jogar games eletrônicos e que na maioria da vezes utilizavam o smartphones para tal fim.

A priori formamos uma equipe multidisciplinar, devidamente cadastrada na Coordenação de Extensão do Campus IFPB Cajazeiras, em forma de um projeto de extensão voluntário que visou colaborar, voluntariamente, com desenvolvimento do ambiente educacional gamificado. A equipe foi composta por 3 discentes do curso de Tecnólogo em Análise e Desenvolvimento de Sistemas (ADS) do IFPB, Campus/Cajazeiras, que programaram o ambiente, e 3 docentes da disciplina de português e literatura, que facilitaram a interação e o contato com os alunos voluntários, além de terem contribuído com o levantamento de requisitos. Em seguida, desenvolvemos as seguintes atividades. Através da figura 2 abaixo, representaremos o passo a passo de como se deu o desenvolvimento do ambiente gamificado:

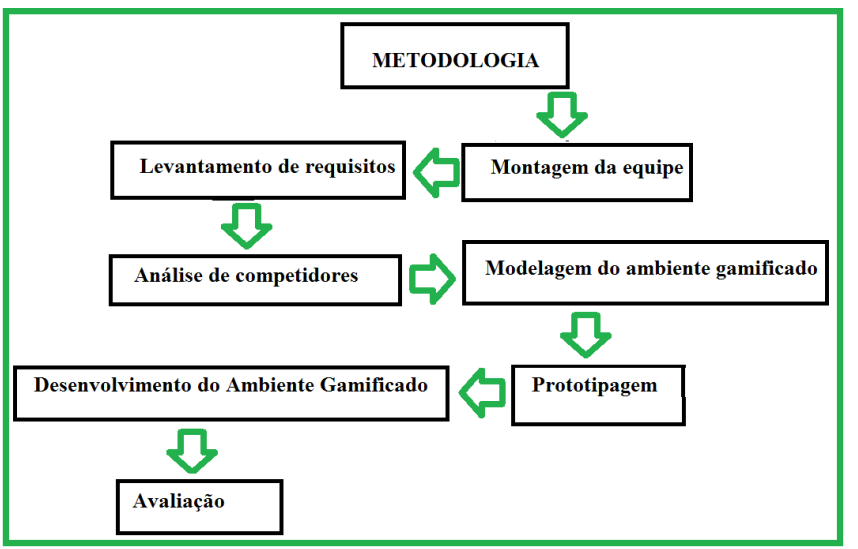

Figura 2 - Fluxograma do processo de desenvolvimento do ambiente gamificado. Fonte: Os autores.

\subsection{Descrição do Ambiente Gamificado Crealit}

O produto educacional da nossa pesquisa trata-se de um ambiente gamificado denominado de Literary Creativity (Crealit), que está em análise de registro de software pelo Núcleo Inovação Tecnológica (NIT/IF SertãoPE). A finalidade do Crealit é ser utilizado nas aulas de literatura como uma ferramenta auxiliadora e motivadora do processo de construção do conhecimento, através do incentivo à leitura de livros clássicos da literatura brasileira de forma lúdica. Ver imagens do jogo abaixo nas figura 3: 


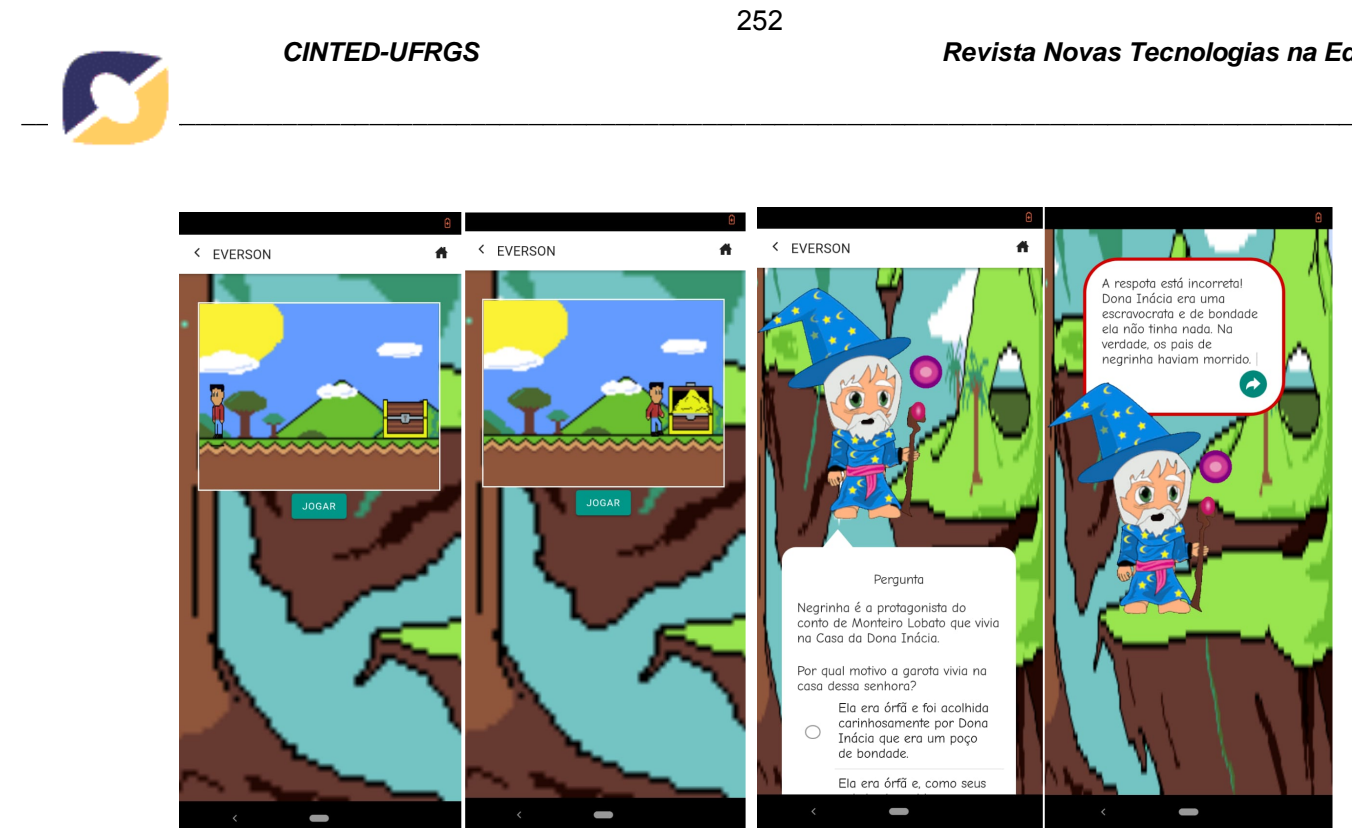

Figura 3 - À esquerda animação do caçador de medalha; à direita o avatar do jogo dando um feedback sobre uma questão que foi incorretamente respondida pelo jogador. Fonte: Os autores

Para o desenvolvimento foi utilizado o framework Ionic Angular, que é uma variação da linguagem de programação javascript, de nome Typescript, e o Firebase como banco de dados. Inicialmente, apresentaremos os protótipos construídos com base nos requisitos identificados na literatura (análise de competidores) e o questionário investigado com o professor, como parte do desenvolvimento da proposta do ambiente gamificado que batizamos como Literary Creativity (Crealit).

\subsection{Componentes e mecânicas gamificadas no ambiente Crealit}

Os componentes de uma gamificação “[...] são aplicações específicas visualizadas e utilizadas na interface do jogo" (COSTA; MARCHIORI, 2015, p. 50). O Crealit Recebeu os seguintes componentes: medalhas, ranking, avatar, Animação e pontuação, descritos no quadro 1 abaixo:

Quadro 1 - Lista de componentes gamificados no ambiente Crealit

\begin{tabular}{|l|l|}
\hline \multicolumn{2}{|c|}{ COMPONENTES GAMIFICADOS NO CREALIT } \\
\hline Componente & \begin{tabular}{l}
\multicolumn{1}{c|}{ Descrição } \\
O Crealit premiará os jogadores com 6 medalhas: Bronze, Prata, \\
Ouro, Platina, Diamante e Esmeralda, para o ranking geral e Ouro, \\
Prata e Bronze dentro de cada história específica. A utilização de \\
medalhas no Crealit tem como finalidade recompensar aqueles \\
jogadores que se empenharem em conseguir os melhores resultados \\
no jogo. De acordo com Sena e Coelho (2012), reforçam que quando \\
há uma determinada premiação envolvida, a mesma, inclina os \\
sujeitos envolvidos a sentirem-se mais motivados a realizarem as \\
atividades propostas, até mesmo desenvolverem um comportamento \\
mais competitivo.
\end{tabular} \\
\hline \multirow{2}{*}{ Ranking } & $\begin{array}{l}\text { O Crealit possui dois rankings: um geral - mostrando a pontuação que } \\
\text { o jogador conseguiu em todas as aventuras que ele jogou, e um } \\
\text { específico mostrando a colocação em uma aventura específica. }\end{array}$ \\
\hline
\end{tabular}




\begin{tabular}{|l|l|}
\hline \multirow{3}{*}{ Avatar } & $\begin{array}{l}\text { O Crealit conta com um avatar: o Mestre - responsável por toda a } \\
\text { mediação do jogo. Os avatares podem ser descritos como um híbrido } \\
\text { entre humanos e não-humanos e têm o papel de mediador entre o } \\
\text { universo do jogo e o universo do jogador (COLEN; MELO, 2010). }\end{array}$ \\
\hline Animação & $\begin{array}{l}\text { O Crealit conta com uma animação chamada de Caçador de } \\
\text { Medalhas: trata-se de um personagem que aparece no início das } \\
\text { aventuras abrindo o baú de medalhas, convidando os jogadores para a } \\
\text { disputa. }\end{array}$ \\
\hline Pontuação & $\begin{array}{l}\text { Para receber as medalhas os jogadores deverão avançar os níveis do } \\
\text { jogo, no caso do ambiente gamificado Crealit quanto menos } \\
\text { tentativas realizadas para acertar as questões mais pontos serão } \\
\text { angariados. A pontuação também é importante para incitar a } \\
\text { competição. Mais detalhes sobre o sistema de pontuação do Crealit } \\
\text { poderão ser vistos na próxima seção, que trata das mecânicas. }\end{array}$ \\
\hline
\end{tabular}

Fonte: Os Autores.

O Crealit é dividido em aventuras, cada aventura corresponderá a um livro que o professor optar por gamificar. Os desafios do Crealit serão em forma de questões com alternativas relacionadas ao livro gamificado. Para maiores esclarecimentos consultar o quadro 2 abaixo:

Quadro 2 - Sistema de pontuação do Crealit

\begin{tabular}{|c|c|}
\hline \multicolumn{2}{|c|}{ Pontuação atribuída a quantidade de tentativas } \\
\hline Primeira tentativa & 5 pontos \\
\hline Segunda tentativa & 3 pontos \\
\hline Terceira tentativa & 2 pontos \\
\hline Quarta tentativa & 1 ponto \\
\hline Quinta tentativa & 0,5 ponto \\
\hline
\end{tabular}

Fonte: Os autores.

O jogo é iniciado quando o discente clica na animação do caçador de medalhas (ver figuras 3), assim que a animação abre o baú de medalhas aparecerá o mestre, na tela seguinte. $\mathrm{O}$ mestre é o avatar que apresenta/media, através de balões de textos, a história (aventuras) que será jogada. Logo em seguida são apresentadas nas telas perguntas, sobre a história, com no máximo cinco alternativas.

O aplicativo oferece duas opções de cadastro: docente e discente. Apenas na conta de docente o usuário terá as permissões para criar as histórias/aventuras. A partir do livro que o professor escolher para gamificar ele irá cadastrar as informações que serão disponibilizadas para os discentes em forma de jogo. Para mais detalhes consultar o manual do docente (https://bityli.com/UffQ1) e do discente (https://bityli.com/KJbYV).

$\mathrm{Na}$ próxima seção traremos os dados que foram analisados com base nas respostas recebidas, via questionários, aplicados para os voluntários da pesquisa. 


\section{Resultados e discussão}

A avaliação do Crealit deu-se em 4 fases. Contudo, antes de cada fase avaliativa os voluntários foram, previamente, informados a respeito da natureza de cada tópico avaliado através dos questionários (ver figura 1). Fase 1- A avaliação por parte dos especialistas, que ofereceu subsídios para a etapa de ajustes ; Fase 2 - Aplicação de um questionário que nos forneceu informação a respeito dos discentes voluntários, com foco na disponibilidade (equipamentos) e engajamento tecnológico para avaliar o Crealit; Fase 3 - Avaliação por parte dos discentes visando verificar a contribuição do produto educacional no incentivo à leitura de livros clássicos ; Fase 4 - Avaliação por parte dos docentes, visando verificar a contribuição do produto educacional como uma ferramenta de auxílio pedagógico no ensino de literatura brasileira.

Resultado da primeira $1^{\mathrm{o}}$ fase que envolveu 6 voluntários: 3 docentes e 3 discentes, todos do Instituto Federal do Sertão Pernambucano (IF Sertão-PE), Campus Petrolina. Inicialmente foi questionado experiência com o desenvolvimento de jogos educacionais, apenas os 3(três) docentes voluntários afirmaram ter alguma experiência.

Nessa avaliação os feedbacks do voluntários foi imprescindível, pois trouxeram críticas que contribuíram com: 1) a melhora da interface gráfica e a experiência do usuário; 2) a inserção de animações no ambiente; 3) a inserção de um ranking melhorado oferecendo mais informações para os discentes e docentes.

Resultados obtidos na $2^{\text {a }}$ fase avaliativa com discentes (33 voluntários): nessa fase procuramos mapear informações que nos dariam subsídios para a fase de avaliação do Crealit na prática. Para tanto, nos inteiramos de que todos os voluntários possuíam smartphone, com as configurações mínimas para instalação do aplicativo (2GB de memória RAM (mínimo), e pelo menos 2GB de armazenamento disponível); Se os mesmo tinham a cultura de instalar aplicativos; se possuíam facilidade em lidar com ferramentas tecnológicas; se tinham conhecimento do que se trata uma gamificação e se já chegaram a utilizar algum ambiente gamificado para fins de aprendizagem formal; e por fim se possuíam o hábito de jogar, e caso positivo se utilizavam o smartphone.

Resultados da $3^{\circ}$ fase ( 38 voluntários): foi nessa fase que os voluntários puderam testar o Crealit, após jogar duas aventuras baseadas no Livro A hora da Estrela (Clarice Lispector) e do Conto Negrinha (Monteiro Lobato), para em seguida responderam um questionário, bastante detalhado. As perguntas do questionário foram norteadas pelos seguintes tópicos: 1) Tópico Motivação: Critério Atenção; Critério Relevância; Critério confiança; Critério satisfação; 2) Tópico Experiência do usuário: Critério Imersão; Critério Desafio; Critério Habilidade / Competência; Critério Divertimento; 3) Tópico Conhecimento: Critério Conhecimento. Por fim, deixamos uma questão aberta para que os voluntários ficassem à vontade para opinar a respeito do Crealit. Tendo como norte os tópicos citados anteriormente, os voluntários responderam mais de 60 questões.

No que se refere à satisfação, medida através de uma escala de Likert de 1 a 5 , $84,2 \%$ dos respondentes ficaram satisfeitos com o Crealit. Acreditamos que o nosso teste foi bastante exitoso e esperamos poder aperfeiçoar cada vez mais o ambiente nas próximas versões. Para mais detalhes ver gráfico 1 abaixo: 


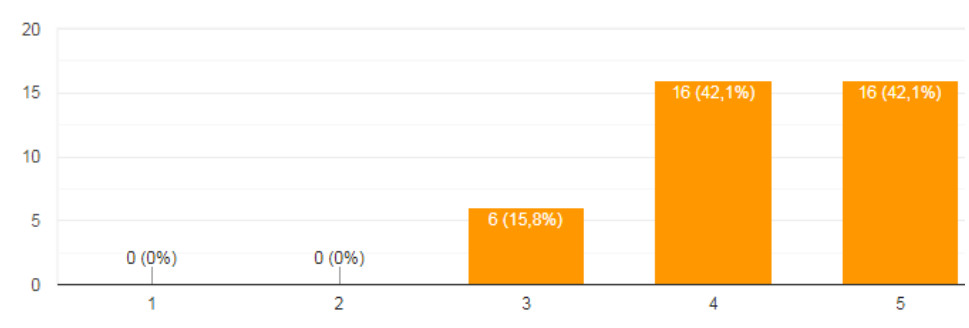

Gráfico 1 - Grau de satisfação dos voluntários. Fonte: os autores.

Após a análise dos questionários chegamos às seguintes conclusões: o Crealit mostrou-se como uma ferramenta impulsionadora do incentivo à leitura, uma vez que os voluntários jogaram uma aventura, com um conto que já haviam realizado a leitura e com um livro ao qual não haviam realizado a leitura. Traremos a seguir alguns dos depoimentos deixados pelos voluntários:

Discente B: "É uma forma bem prática e rápida de verificar se compreendemos as obras passadas pelos professores." Discente C: "Muito bom, completo e simples de usar. Além de trazer grande aprendizado e melhorar a fixagem de temas relacionados ao livro." Discente D: "É um projeto incrível quem tem um bom desempenho e nos ajuda a fixar melhor os assuntos abordados nos livros, além de nos fazer trabalhar o nosso raciocínio na hora de responder as questões."

Os voluntários também deixaram claro que Crealit poderá contribuir como uma ferramenta de apoio ao docente dentro e fora da sala de aula:

Discente F: "É um ótimo aplicativo. Gostei bastante. Os professores poderiam utilizar com a gente. Parabéns para quem criou o aplicativo, só sucesso.” Discente G: "Achei a ferramenta muito interessante e inovadora, já que nunca havia tido contato com algo similar e gostaria que os professores utilizassem ferramentas semelhantes, iria tornar o estudo melhor e mais inovador."

Os voluntários também concluíram que o Crealit poderá contribuir com a aprendizagem de conteúdo voltado para provas e seleções:

Discente I: "Interessante! Ótimo para ser usado após a leitura de um livro, assim fixaremos melhor o que a história tratava e também pode ser uma alternativa quanto ao estudo de questões que caem em vestibulares ou no ENEM.

Também expressaram como foi interessante aprender de uma forma lúdica:

Discente K: "É um ambiente bem legal, principalmente porque se trata de aprender de uma maneira divertida” Discente L: “O Crealit é muito bom e interessante, pois nos trás uma forma divertida de aprendizagem. Ele também nos incentiva a ler e digamos assim: Fazer mais pontos do que os outros".’Discente M: "Eu achei um meio bem didático para novas aprendizagens, seria bem legal se fosse implantados em escola dos nosso município e de vizinhos por ser uma atividade bem lúdica e de fácil entendimento.”

Os voluntários também nos deixaram algumas críticas que contribuirão com melhorias que poderemos implantar em versões posteriores do Crealit:

Discente O: "Muito bom o projeto, mas creio que possa melhorar muito ainda". Discente P: "É uma plataforma simples, bacana, mas um pouco mal-acabada."Discente Q: "É um meio bastante interessante de estimular os conhecimentos. Deve investir nos gráficos, melhora-los".

Por fim, na fase 4 (2 voluntárias) as docentes A e B, que responderam ao questionário, aprovaram o Crealit como uma ferramenta de apoio pedagógico e concordaram totalmente que o Crealit poderá contribuir também como uma ferramenta de e estímulo/incentivo à leitura dos discente. Como sugestão sentiram a necessidade do Crealit possuir um chat para que os alunos possam trocar experiências, assim como a possibilidade de criar seu avatar ao realizar o cadastro no ambiente. 


\section{Conclusões}

De acordo com a leitura dos dados qualitativos e quantitativos, levantados através da aplicação de questionários, os discentes voluntários sinalizaram que o Crealit poderá colaborar com a aprendizagem de uma forma inovadora/diferente, contribuindo como uma ferramenta de apoio ao docente dentro e fora a sala de aula, como também, com a aprendizagem de conteúdo voltado para as provas e seleções, podendo ser utilizado como uma ferramenta de incentivo à leitura (principal objetivo dessa pesquisa), proporcionando uma aprendizagem de forma lúdica.

Contudo não podemos olvidar que a leitura do livro jamais deverá ser substituída pela experiência proporcionada pelo Crealit, pois o objetivo da utilização das mecânicas de jogos em nossa pesquisa teve como foco fomentar a leitura dos livros clássicos da literatura brasileira, de acordo com Mendonça $(2015$, p. 208) "[...] o ato de jogar proporciona ao aluno um importante conhecimento prévio que, acreditamos, facilitará consideravelmente sua imersão na leitura da obra que foi adaptada ao jogo". Medonça (2015) ainda enfatiza a importância do papel do professor no fomento ao incentivo à leitura, que de forma nenhuma poderá limitar-se apenas a um jogo.

Por fim, chegamos a conclusão que o Crealit demonstrou ter potencial para ser utilizado por discentes e docentes no processo de ensino e aprendizagem do conteúdo dos livros clássicos de literatura brasileira. Em trabalhos futuros buscaremos avaliar a questão do engajamento dos voluntários.

\section{Referências}

BRASIL. Base Nacional Comum Curricular. Brasília: [s.n.], 2018. Disponível em: http://basenacionalcomum.mec.gov.br/images/BNCC_EI_EF_110518_versaofinal_site. pdf. Acesso em: 18 de agosto 2019.

COLEN, Edvaldo Melo; MELO, Maria de Fátima Aranha de Queiroz e. Os avatares como mediadores no jogo de papéis. Pesquisas e Práticas Psicossociais, São João del-Rei, v. 5, n. 1, p. 17-29, janeiro/julho 2010. Disponível em: https://www.ufsj.edu.br/portal2-repositorio/File/revistalapip/volume5_n1/colen_e_queir oz_e_melo.pdf. Acesso em: 03 de jun. 2019.

COSTA, Amanda Cristina Santos; MARCHIORI, Patricia Zeni. Gamificação, elementos de jogos e estratégia: uma matriz de referência. InCID: R. Ci. Inf. e Doc., Ribeirão Preto, v. 6, n. 2, p. 44-65, set. 2015/fev. 2016. Disponível em: https://www.revistas.usp.br/incid/article/download/89912/103928/. Acesso em: 03 de maio 2019.

CUNHA, Luísa Margarida Antunes da. Modelos Rasch e escalas de Likert e Thurstone na medição de atitudes. 2007. 78 f. Dissertação (Mestrado em Probabilidades e Estatística) - Universidade de Lisboa, Faculdade de Ciências, Lisboa, 2007. Disponível em: http://repositorio.ul.pt/bitstream/10451/1229/1/18914_ULFC072532_TM.pdf. Acesso em: 05 de junho 2019. 
FALCÃO, Adair Perdomo. GamersBook: Sistema gamificado de apoio ao aprendizado. 2015. 61 f. Monografia (Trabalho de Conclusão de Curso) - Curso Superior de Licenciatura em Informática, Universidade Tecnológica Federal do Paraná, Câmpus Francisco Beltrão. Francisco Beltrão, 2015. Disponível em: http://repositorio.roca.utfpr.edu.br/jspui/bitstream/1/6872/1/FB_COLIN_2015_2_01.pd f.Acesso em: 31 de julho 2019.

FIALHO, Flávia Andrade; DIAS, Ieda Maria Ávila Vargas; REGO, Marisa Palacios da Cunha e Melo de Almeida. Instrumento de coleta de dados quantitativos em pesquisas de bioética realizadas com crianças. Tempus Actas de Saúde Colet. Brasília, v. 9. n. 3 , p. 179-186, set, 2015. Disponível em: https://www.tempusactas.unb.br/index.php/tempus/issue/view/113. Acesso em: $15 \mathrm{de}$ janeiro 2021.

KIM, Bohyun. The Popularity of Gamification in the Mobile and Social Era. Library Technology Reports, Chicago, v.5, n. 2, p. 5-9, fev./mar. 2015. Cap. 1. Disponível em: https://journals.ala.org/index.php/ltr/article/view/5628/6944. Acesso em: 12 de abril 2019.

KLOCK, Ana Carolina Tomé et al. Análise das técnicas de Gamificação em Ambientes Virtuais de Aprendizagem. Renote, Joinville-SC, v. 12, n. 2, dez. 2014. p. 1-2. Disponível em: https://seer.ufrgs.br/renote/article/view/53496/33013. Acesso em: 28 de abril de 2021.

LIU, Min. Motivating students to learn using a game-based learning approach: Gaming and education issue. Texas Education Review, v. 2, n. 1, p. 117-128, 2014. Citado na página $16 . \quad$ Disponível em: https://journals.tdl.org/txedrev/index.php/txedrev/article/view/46/39. Acesso em: $31 \mathrm{de}$ julho 2019.

MENDONÇA, A. N. F. de. O Jogo digital como incentivo da leitura em jovens do ensino médio. 2015. 218 f. Tese (Doutorado em Informática) - Programa de Pós-Graduação em Informática, Universidade Federal do Rio Grande do Sul, Porto Alegre, 2015. Disponível em: https://lume.ufrgs.br/handle/10183/128890. Acesso em: 12 de abril 2019.

PRENSKY, Marc. Digital natives, digital immigrants part 1. On the horizon, [s.1.], v. 9, n. 5, p. 1-6, 2001. Disponível em: https://www.emeraldinsight.com/toc/oth/9/5. Acesso em: 14 de abr. 2019

SAVI, Rafael et al. Proposta de um modelo de avaliação de jogos educacionais. Rev. Novas Tecnologias na Educação, Porto Alegre, v. 8, n. 3, p. 1-12, dez. 2010. Disponível em: https://seer.ufrgs.br/renote/article/view/18043/10630. Acesso em: 10 de abril 2019.

SENA, Alexandre; COELHO, Dennis Kerr. Motivação dos jogadores de videogame: uma breve visão sobre as técnicas de engajamento. In: SIMPÓSIO BRASILEIRO DE JOGOS E ENTRETENIMENTO DIGITAL, 9. Anais Eletrônicos [...], Brasília: SBGames, $2012 . \quad$ Disponível http://www.sbgames.org/sbgames2012/proceedings/papers/cultura/C_S4.pdf. Acesso em: 03 de jun. 2019. 